\title{
A case of Hemorrhagic Bullous Morphea
}

\author{
Hyeree Kim, Hei Sung Kim, Sang Hyun Cho and Jeong Deuk Lee* \\ Department of Dermatology, Incheon St. Mary's Hospital, College of Medicine, The Catholic \\ University of Korea, Seoul, Korea
}

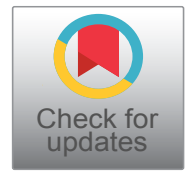

*Corresponding author: Jeong Deuk Lee, Department of Dermatology, Incheon St. Mary's Hospital, College of Medicine, The Catholic University of Korea, 56 Donsuro, Bupyeong-gu, Incheon, 403-720, Korea, Tel: 82-32-8205100, Fax: 82-2-506-9514, E-mail: leejd@olmh.cuk.ac.kr

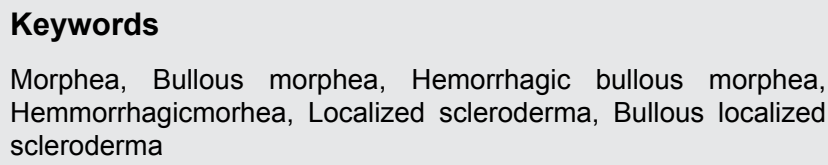

Morphea, Bullous morphea, Hemorrhagic bullous morphea, Hemmorrhagicmorhea, Localized scleroderma, Bullous localized scleroderma

Bullous morphea is a rare form of localized scleroderma (morphea) characterized by bullae on or around an atrophic morphea plaque [1]. The cause of bullae formation in morphea is multifactorial, with lymphatic obstruction from the sclerodermatous process being considered as the most likely cause [2]. Bullous morphea is a rare that represents about $7.5 \%$ of all cases of scleroderma [3]. To our knowledge, hemorrhagic bullous morphea have been reported only five cases in the world literatures [3,4]. We herein report a rare case of hemorrhagic bullous morphea.

A 75-year-old female presented with a painful, solitary, $9 \times 6 \mathrm{~cm}$ sized, erythematous, sclerotic plaque surrounded by a purpuric bullae on the back (Figure 1). The bullae contained hemorrhagic fluid. She said the lesion started as solitary erythematous patch, but gradually increased in size, gradually showed sclerotic changes and eventually arised hemorrhagic bullous lesion within a month. She denied of any trauma history. The family history for autoimmune diseases was negative. The following laboratory tests, including routine complete blood count, routine chemistry, urine analysis and ANA were within normal limits. We did a biopsy for the diagnosis.

Histopathologic findings of the sclerotic plaque revealed thick collageneous tissue deposition in the superficial dermis, and chronic inflammatory cells infiltration in the dermis. The adnexa appeared reduced in number. (Figure 2). There were no infiltrations of IgG, IgA, IgM, C1q and C3, and minimal focal infiltration of fibrinogen. According to histologic and clinical features, we diagnosed this case as hemorrhagic bullous morphea.

After a month of daily wet dressing and topical mupirocin applying, the bullae spontaneously regressed. There is no recurrence after 6 months.

Peterson et al. proposed that morphea can be classified into five groups: plaque, generalized, bullous, linear, and deep [1]. Among these types, bullous morphea is quite rare, and hemorrhagic bullous morphea are reported only five cases worldwide (Table 1) [3-6].
The pathogenesis of bullous morphea is still unknown, but several mechanisms have been proposed, such as inflammation, lymphangiectasis and immune-mediated aggression [3]. The current belief is bullous lesions are more frequently observed on the lower extremities, which suggests that lymphatic obstruction, combined with increased hydrostatic pressure, leads to bullae formation $[3,1,2]$. But Angel reported three cases of bullous morphea that did not show any histopathological feature suggestive of lymphatic blockage, so insisted some signs supporting local trauma as a cause [3]. Pautrier also suggested that vascular changes like arterities and phlebosclerosis play role in bullae formation, so that hemorrhagic bullae can occur in bullous morphea, although rare. Daoud found that major basic

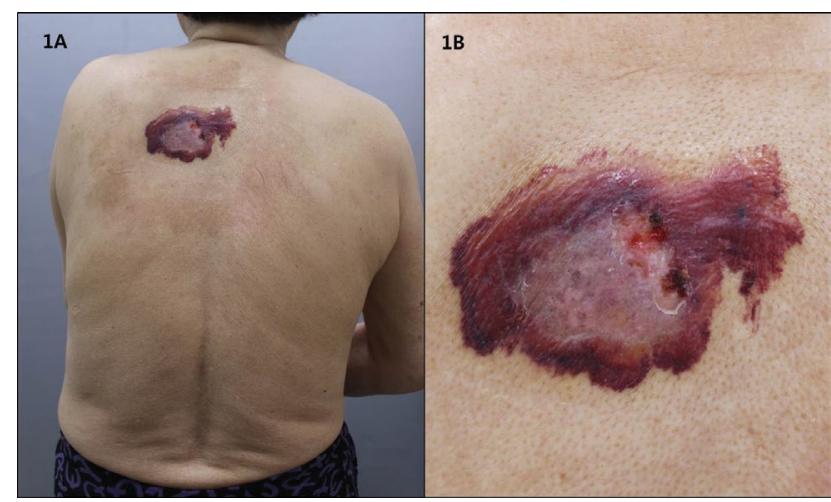

Figure 1(A): There is a $9 \times 6 \mathrm{~cm}$-sized, erythematous, sclerotic plaque surrounded by apurpuric bullae on the back.

Figure 1(B): The Serohemorrhagic fluid in the surrounding tense bullae.

Table 1: Summary of report of Hemorrhagic bullous morphea

\begin{tabular}{|l|c|c|}
\hline \multicolumn{1}{|c|}{ Case } & Sex/age & Site \\
\hline \multirow{2}{*}{ Angel et al. (2015) } & $55 / \mathrm{F}$ & Trunk and arm \\
\cline { 2 - 3 } & $69 / \mathrm{M}$ & Thigh \\
\cline { 2 - 3 } Thomas CG. (2002) & 22/M & Back \\
\hline Tostiet al. (1989) & 20/F & $\begin{array}{c}\text { Inframammarian folds, axillary folds, lower } \\
\text { abdomen, upper extremities and inguinal } \\
\text { folds }\end{array}$ \\
\hline
\end{tabular}

Citation: Kim H, Kim HS, Cho SH, Lee JD (2015) A case of Hemorrhagic Bullous Morphea. J Dermatol Res Ther 1:011 

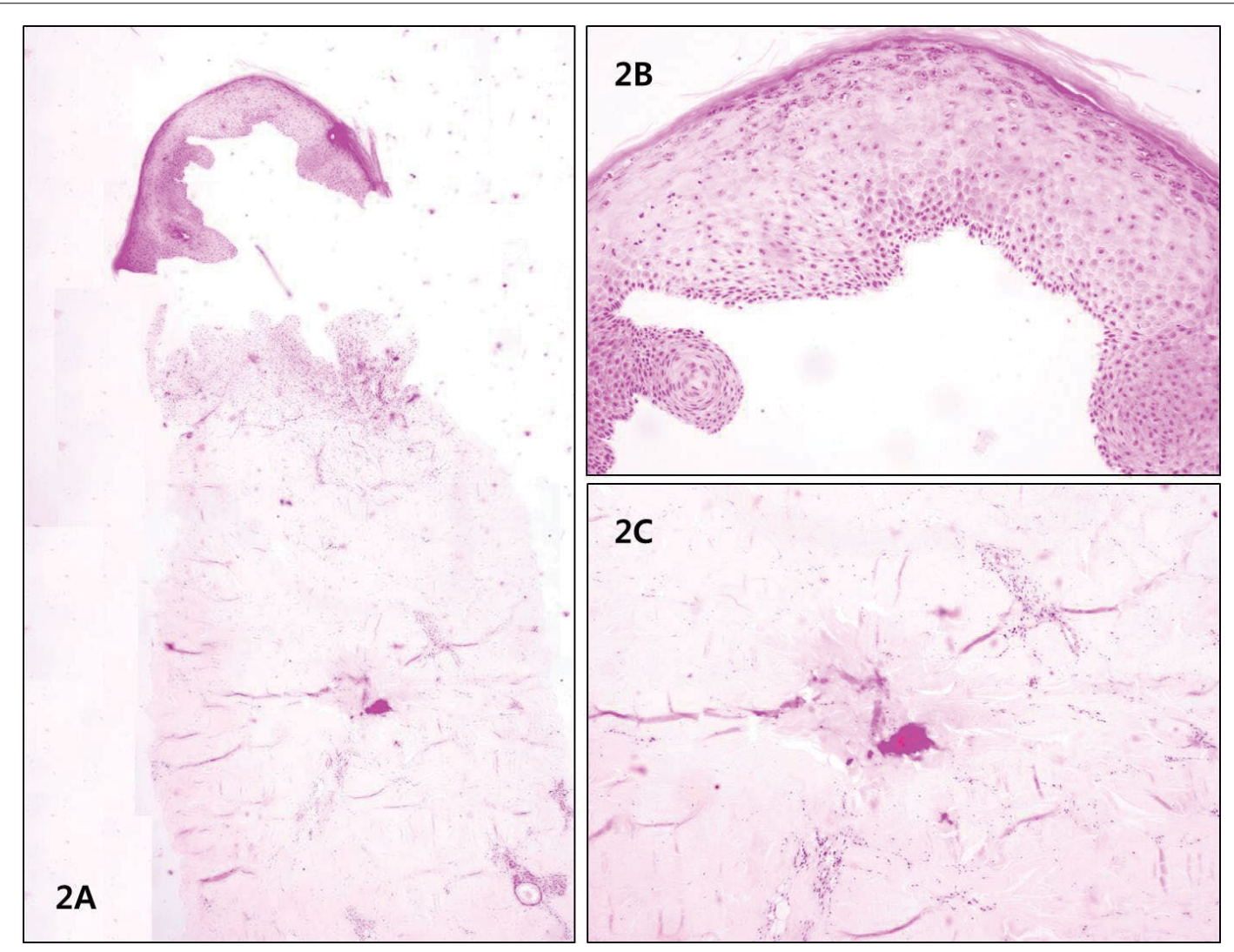

Figure 2(A): Histopathologic findings of the sclerotic plaque revealed thick collageneous tissue deposition in the superficial dermis, and chronic inflammatory cells infiltration in the dermis. (A: $H \& E \times 40$ )

Figure 2(B): Histopathologic findings of the sclerotic plaque revealed thick collageneous tissue deposition in the superficial dermis, and chronic inflammatory cells infiltration in the dermis. (B: $\mathrm{H} \& \mathrm{E} \times 100)$

Figure 2(C): Histopathologic findings of the sclerotic plaque revealed thick collageneous tissue deposition in the superficial dermis, and chronic inflammatory cells infiltration in the dermis. (C: $H \& E \times 100)$

protein is responsible for blister formation in at least some cases of morphea [2]. Skin biopsy should be done for diagnosis. The blood autoantibody tests may help doing differential diagnosis with other autoimmune disease including systemic sclerosis. Numerous agents, such as corticosteroids, antimalarial drugs, colchicine, retinoids, salazopyrin, pentoxifilline, etc. have been reported to be effective for treating bullous morphea. Despite these large numbers of reported treatments, no consistent recommendations exist for treatment. Prognosis of hemorrhagic bullous morpheais rarely life-threatening like other type of morphea, but significant joint deformities are usually common in linear- and profunda-type bullous morphea [3]. It maybe self-limited, but has a remitting relapsing or chronic course producing significant disorder burden over time.

As stated above, bullous morphea is very rare disease. And to our knowledge, hemorrhagic bullous morphea is much less, which have only been previously reported in the literature by Hewitt in 1959, by Antonella in 1990 [4] and by Angel 2015 [3]. This case was described in order to provide a report as a very rare case of hemorrhagic bullous morphea.

\section{References}

1. Jia $\mathrm{H}$, Chen $\mathrm{XH}$, Shi JH, Zhao CX, Cao YH, et al. (2002) A case of bullous morphea reported in mainland China. Int J Dermatol 41: 949-950.

2. Daoud MS, Su WP, Leiferman KM, Perniciaro C (1994) Bullous morphea: clinical, pathologic, and immunopathologic evaluation of thirteen cases. J Am Acad Dermatol 30: 937-943

3. Angel FF, Michelle GT, Fátima TF, Linda GH, Elena M, et al. (2015) Three cases of bullous morphea: histopathologic findings withimplications regarding pathogenesis. J Cutan Pathol 42: 144-149.

4. Tosti A, Melino M, Bardazzi F (1989) Hemorrhagic bullous lesions in morphea. Cutis 44: 118-119.

5. Gallagher TC (2002) Bullous morphea. Dermatol Online J 8: 11.

6. Kavala M, Zindanci I, Demirkesen C, Beyhan EK, Turkoglu Z (2007) Intertriginous bullous morphea: A clue for the pathogenesis? Indian J Dermatol Venereol Leprol 73: 262-264. 